\title{
VARIATION OF CHIASMA FREQUENCY IN AND BETWEEN NATURAL POPULATIONS OF ACRIDIDAE
}

\author{
J. F. BARKER *
}

Cancer Research Unit, The University, Sheffield, 10

\section{INTRODUCTION}

Received 24.9.59

Given any significant heterozygosity the genetic stability and variability of populations must be affected by any variation of chiasma frequency that may occur (Darlington, I939; Mather, I943; Thoday, I953). Natural populations of grasshoppers (Myrmeleotettix maculatus (Th.) and Chorthippus parallelus (Zett.)) have therefore been examined by analysis of metaphase chiasma frequencies in males to see whether such variation is to be found.

\section{MATERIAL}

The populations sampled were in the north and south of England (the Sheffield region, and the Ascot and New Forest regions respectively). The grasshoppers were collected in the early evening and their testes fixed within two hours of collection in Strong Flemming's solution. The sections were stained with crystal violet. Chiasmata were counted in five cells per individual and usually in eight individuals per sample.

\section{RESULTS}

\section{(i) Chiasma frequencies}

Though the experimental results are limited they seem to demonstrate that variation of chiasma frequency does occur in and between these natural populations. In both Myrmeleotettix and Chorthippus it was found (i) that there were significant differences between individuals within populations (compare Elliott, I954), and (ii) samples from different areas had significantly different chiasma frequencies.

In Myrmeleotettix the two high altitude (over I, ooo feet) northern populations had lower chiasma frequencies (mean $\left.=14 \cdot 3^{6}\right)$ than the two southern populations which were at low altitudes (mean $\left.=I_{5} \cdot 18\right)$. An analysis of the relevant data is given in table $I$. These differences in chiasma frequency between areas might be related to climate: the high altitude northern populations were found in cooler, wetter areas than the southern populations.

Samples of Myrmeleotettix were also obtained from three medium and low altitude northern populations and their chiasma frequencies varied between those characteristic of the high altitude northern and those characteristic of the southern populations.

All the populations of Chorthippus were at low altitudes. Data were obtained from one northern population (two samples) and two southern populations (Ascot and New Forest). The samples from the north (mean = I 4.54) had a significantly lower chiasma frequency $(\mathrm{P}<0 . \mathrm{O})$ than those from the south (mean $\left.=I 5^{\circ} 5^{I}\right)$.

\footnotetext{
* Formerly : The Zoology Department, Sheffield University.
} 
It seems unlikely that the differences of chiasma frequency are directly caused by summer environmental differences for the following reasons :(a) One population of Chorthippus was sampled both at mid-day and in the early evening. The two samples had similar chiasma frequencies. (b) Five populations (four Myrmeleotettix and one Chorthippus) were each sampled in

TABLE I

Analysis of variance of number of chiasmata in the Myrmeleotettix field samples from the high altitude northern and low altitude southern populations (means listed in table 2)

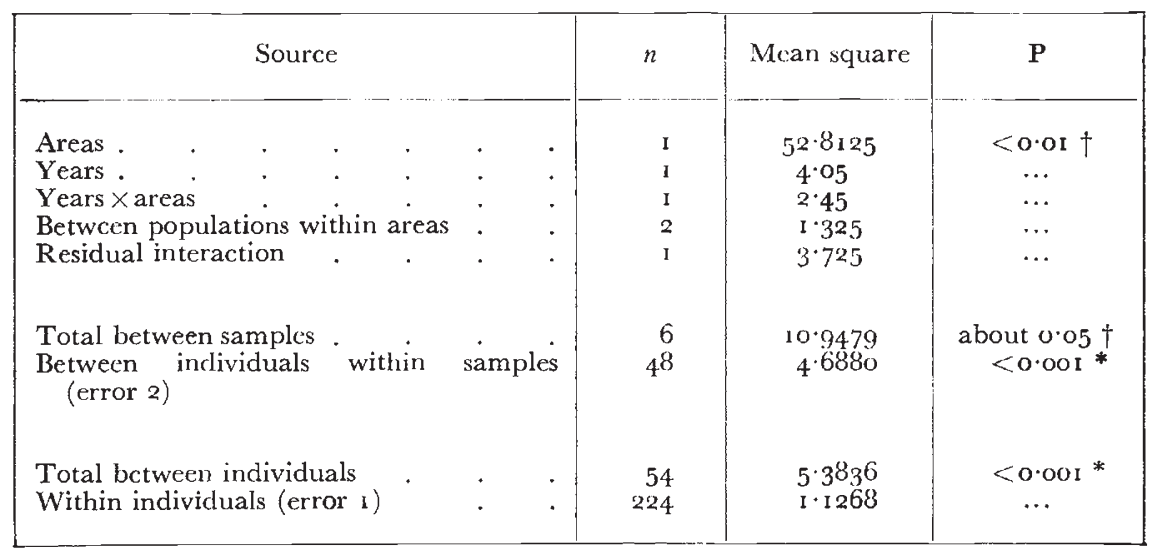

* Compared with error I. $\quad \dagger$ Compared with crror 2.

TABLE 2

Chiasma frequencies in some of the Myrmeleotettix samples

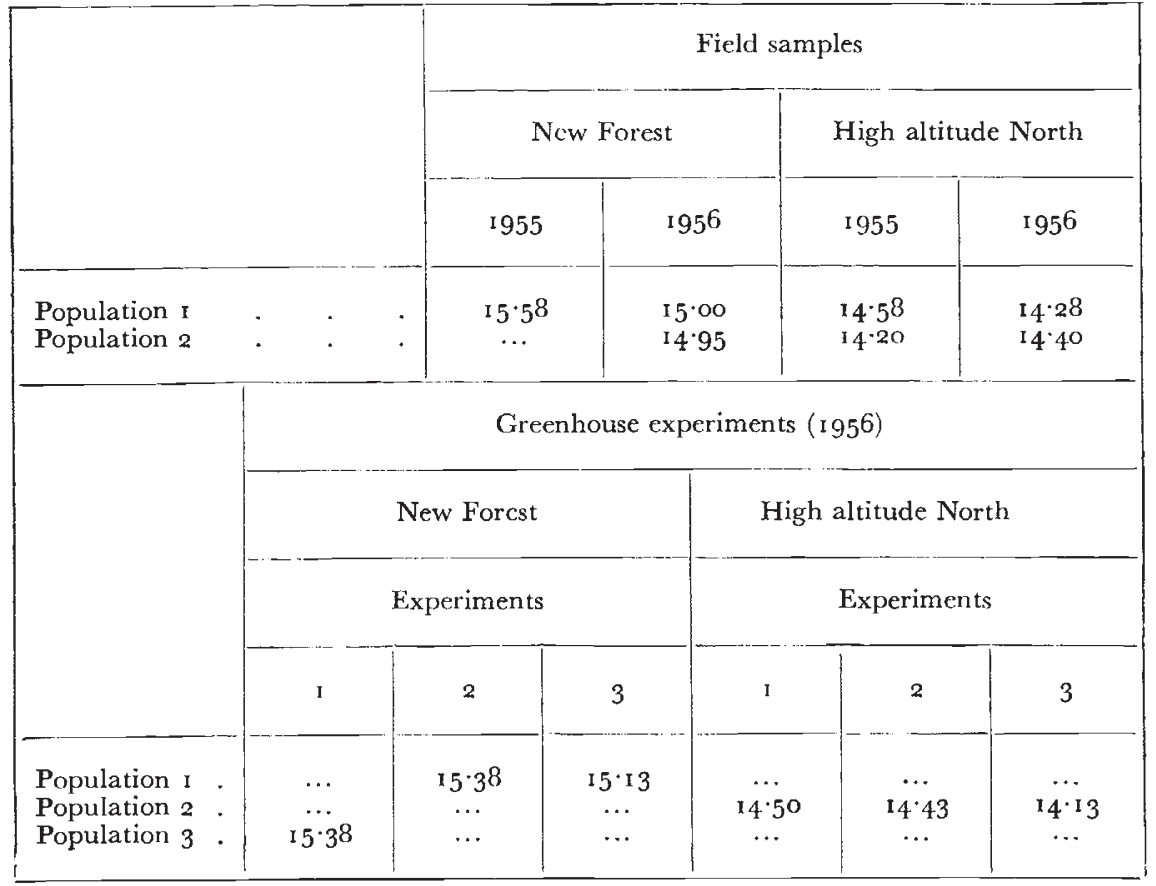


different months of the same summer. There was no significant difference between the samples collected earlier and those collected later in the summer. (c) Four populations were sampled in both 1955 and 1956 and there was no significant difference between years, though the summer of 1955 was hot and dry and that of 1956 very cold and wet. (d) Three experiments were carried out, two starting with adults and one with fourth instars, to test whether the differences of chiasma frequency between populations of Myrmeleotettix would still be evident if individuals from different populations were kept together in the same environment (a greenhouse in Sheffield) for a few days prior to the time when the chiasmata were actually formed. Analysis of variance showed that the difference between the high altitude and the southern populations was not affected and there was no significant difference between field and greenhouse samples. Table 2 summarises the data.

All these five tests suggest that the differences in chiasma frequency between areas are fairly stable. It seems reasonable to conclude that the southern populations of Myrmeleotettix and Chorthippus have a consistently higher chiasma frequency (and hence more genetic recombination) than certain of the northern populations.

\section{(ii) Supernumeraries}

Supernumerary chromosomes were found in some individuals in five out of the eight populations of Myrmeleotettix studied. Individuals with supernumeraries usually had one or two per cell and these chromosomes were never found paired with members of the "normal" complement at first meiotic metaphase (fig. I).

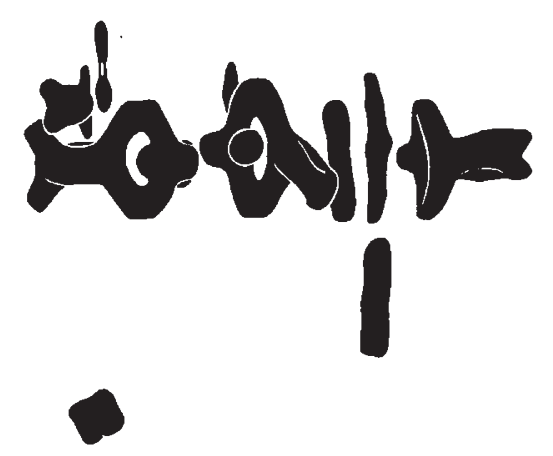

FIG. I.-Ist meiotic metaphase. Myrmeleotettix maculatus. Magnification I200. The rod-shaped sex chromosome and the supernumerary chromosome are seen lying off the metaphase plate.

Supernumerary chromosomes were present in all the southern samples of Myrmeleotettix but not in any of the samples from high altitude northern populations. These chromosomes were also found in a few individuals in two low altitude northern areas. Analyses showed that, within populations, those individuals with supernumeraries had significantly higher chiasma frequencies in the "normal" members of the chromosome complement than did those lacking supernumeraries. Further, no significant difference in chiasma frequency between the high altitude northern areas and the 
southern areas was demonstrable in Myrmeleotettix when individuals with supernumeraries were left out of the analysis. It seems most likely that the supernumerary chromosomes have the effect of raising chiasma frequency in the other chromosomes (compare Mather, 1939) and that their presence is at least partly responsible for the higher chiasma frequencies of the southern populations of Myrmeleotettix. (It must be noted that any chiasmata between or within supernumeraries were ignored throughout the analyses.)

Supernumeraries were not found in Chorthippus, yet there were differences in chiasma frequency between the samples from the north and those from the south in this species, that were similar in magnitude to those found in Myrmeleotettix. It would seem that both species may have developed higher chiasma frequencies in the south and lower in parts of the north but that the regional differences have been produced by different mechanisms. That both species showed similar differences suggests that higher chiasma frequencies may be advantageous in the south (or lower frequencies advantageous in the north). It is therefore possible that supernumeraries were selected in the southern populations of Myrmeleotettix primarily because they affect chiasma frequency, or eliminated from the northern high altitude populations because they raise chiasma frequency.

\section{CONCLUSION}

The results reported are not extensive, but they do suggest that further study of chiasma frequency and supernumerary frequency in natural populations of these species would be well worth while. If such a study could be combined with ecological study to determine for example whether chiasma frequency in marginal populations (such as the high altitude populations of Myrmeleotettix may be) differs consistently from that in the more central populations (compare Carson, 1955) new understanding of natural populations might result.

Acknowledgments.--I would like to thank Dr J. M. Thoday for suggesting this study, Professor L. E. S. Eastham, and all others who helped. I also acknowledge the receipt of Research Fund Grant number 206 from Sheffield University.

\section{REFERENCES}

CARSON, H. L. I955. Variation in genetic recombination in natural populations. 7. cell. comp. Physiol., 45, Suppl. 2, 221-236.

Darlington, c. D. 1939. The Evolution of Genetic Systems. Cambridge University Press.

ELLIOTT, C. G. 1954. Variation in chiasma frequency in natural populations. Proc. gth International Congress of Genetics, part II, 689-69o.

MATHER, K. I939. Competition for chiasmata in diploid and trisomic maize. Chromosoma, I, I 19-129.

MAther, к. I943. Polygenic inheritance and natural selection. Biol. Rev., I8, $32-64$.

Thoday, J. м. 1953. Components of fitness. Symp. Soc. Exp. Biol., 7, 96-113. 